\title{
PEMANFAATAN APLIKASI E-LEARNING UNTUK PEMBELAJARAN MATERI UMUM BERBASIS ANDROID
}

\author{
Widy Saeful Iman ${ }^{1}$, Mei Lestari ${ }^{2}$, Ni Wayan Parwati $S^{3}$ \\ Program Studi Teknik Informatika, Universitas Indraprasta PGRI \\ widy.saeful@gmail.com ${ }^{1}$, mei.lestari6@gmail.com ${ }^{2}$,wayan.parwati@gmail.com ${ }^{3}$ \\ Submitted December 23, 2020; Revised January 29, 2021; Accepted February 2, 2021
}

\begin{abstract}
Abstrak
Aplikasi e-learning merupakan salah satu inovasi yang digunakan dalam pembelajaran. Pembelajaran dengan aplikasi e-learning dapat memberikan kebebasan tempat dan waktu untuk penggunanya. Penelitian ini bertujuan untuk mengembangkan aplikasi e-learning sebagai media pembelajaran yang bernama teman belajar. Pada Teman belajar ini ada dua aktor yang terdiri dari admin dan pengguna. Admin merupakan aktor yang berperan dalam memanage semua aktivitas dalam teman belajar. Pengguna dalam teman belajar ini dapat dibagi menjadi dua fungsi, yaitu sebagai pembuat soal dan pencari soal. Metode yang digunakan dalam mengembangkan teman belajar ini menggunakan model waterfall. Hasil pengujian yang dilakukan pada teman belajar di beberapa smartphone yang berbeda menunjukkan kualitas layout yang dihasilkan baik, serta tidak ditemukan adanya error sehingga dapat disimpulkan bahwa Teman belajar ini berjalan dengan baik sesuai dengan yang diharapkan. Dengan aplikasi teman belajar ini diharapkan dapat memenuhi kebutuhan pengguna dengan berbagai materi umum yang bisa dipilih sesuai dengan yang dibutuhkan.
\end{abstract}

Kata Kunci :aplikasi $e$-learning, pembelajaran materi umum, android

\begin{abstract}
E-learning application is one of the innovations used in learning. Learning with e-learning applications can provide flexibility in place and time for users. This research aims to develop an elearning application as a learning medium called Teman belajar. In Teman belajar, there are two actors consisting of admin and users. Admin is an actor who manage all activities in Teman belajar. Users in this research can be divided into two functions, as an exercise maker and exercise seeker. The method used in developing Teman belajar uses the waterfall model. The result of test on Teman belajar in several different smartphones show that the resulting image quality or layout is good and there are no errors found, so it can be concluded that Teman belajar is going well as expected. With Teman belajar application, it hoped that it can fulfill user needs with various of general materials that can be selected as needed.
\end{abstract}

Key Words : e-learning application, general materials learning, android

\section{PENDAHULUAN}

Aplikasi e-learning merupakan media pembelajaran yang menggunakan teknologi informasi. Berkembangnya aplikasi e-learning ini sebagai salah satu dampak kemajuan teknologi yang semakin pesat dan mengalami akselerasi yang luar biasa. Karena semakin meningkatnya aktivitas pengguna, aplikasi e-learning banyak dijadikan pilihan oleh pengguna yang ingin belajar dan mengupgrade skill dan wawasannya. Aplikasi e-learning dijadikan pilihan karena sifatnya yang fleksibel. Berbeda dengan pembelajaran konvesional yang sifatnya kaku karena terbatas ruang dan waktu, pembelajaran melalui aplikasi e-learning bersifat sebaliknya, yaitu tanpa ada batas ruang dan waktu. Artinya pembelajaran dapat dilakukan di mana saja dan kapan saja. Rohmah mengatakan bahwa pembelajaran dengan aplikasi e-learning dapat menciptakan independent learning, yaitu memberikan kesempatan bagi pengguna untuk memegang kendali atas kesuksesan belajar masing-masing. Artinya pengguna 
diberi kebebasan untuk menentukan kapan akan mulai, kapan akan menyelesaikan, dan bagian mana dalam satu modul yang ingin dipelajarinya terlebih dulu [1].

Meskipun aplikasi e-learning banyak dipilih oleh pengguna, terdapat satu kekurangan utama yang menjadi esensi sekaligus tantangan untuk pengembang aplikasi e-learning. Beberapa aplikasi $e$ learning yang muncul cenderung memiliki kesamaan dalam segi konten sehingga kurang variatif. Di Indonesia, ada beberapa aplikasi e-learning yang populer seperti quipper, zenius, dan ruangguru. Ketiga aplikasi ini menyediakan materi pembelajaran mulai dari jenjang SD-SMA [2]. Ketiga aplikasi ini juga memiliki kesamaan fitur, yaitu pembelajaran yang disediakan berupa video [3]. Ruangguru juga menyediakan fitur ruangguru skillacademy yang berisi pelatihan untuk meningkatkan skill para penggunanya. Namun, keberadaan aplikasi e-learning yang berisi materi umum untuk berbagai cakupan pengguna saat ini masih terbatas.

Banyaknya kesamaan pada aplikasi yang serupa, menuntut kreativitas dalam pengembangan aplikasi yang kompetitif. Selain itu, karena belajar secara mandiri, aplikasi yang unik dan tidak monoton diperlukan agar pengguna tidak bosan. Hal ini untuk membangun ketertarikan dan kenyamanan pengguna sehingga dengan pemanfaatan aplikasi e-learning dengan baik dapat meningkatkan hasil pembelajaran dengan maksimal. Penelitian ini bertujuan untuk mengembangkan aplikasi e-learning sebagai media pembelajaran materi umum yang bernama teman belajar. Teman belajar berisi materi umum untuk pengguna mulai dari SD sampai SMA, profesional, dan juga kalangan umum.

Teman belajar memberikan inovasi yang berbeda dari aplikasi e-learning yang sudah ada sebelumnya di Indonesia. Inovasi tersebut di antaranya menyediakan berbagai materi umum yang tidak hanya untuk pelajar hingga SMA, tetapi juga untuk profesional dan kalangan umum. Pengguna juga dapat memiliki dua fungsi, yaitu sebagai pencari soal dan pembuat soal. Pengguna yang ingin menjadi pembuat soal akan mengikuti tes kompetensi terlebih dahulu. Banyak ditemukan pada aplikasi e-learning latihan soal dan materi yang diambil secara sembarangan dari situs pencarian internet. Hadirnya teman belajar sebagai aplikasi $e$ learning menjadikan latihan soal dan materi yang dibutuhkan pengguna menjadi terverifikasi dengan baik karena dibuat oleh orang yang ahli di bidangnya.

\section{E-learning dalam Pendidikan}

Perkembangan teknologi informasi memberikan perubahan dalam sektor pendidikan. Model pembelajaran yang semula bersifat konvensional, yaitu face to face di dalam ruang kelas dan pada waktu tertentu, kini beradaptasi dengan perubahan model belajar yang bersifat elektronik atau e-learning.

Istilah e-learning pertama kali muncul pada 1999 pertama kali dalam seminar sistem CBT [4]. E-learning merupakan salah satu bentuk model pembelajaran yang difasilitasi dan didukung pemanfaatan teknologi informasi dan komunikasi [5]. E-learning adalah alat atau sistem pendidikan berbasis komputer yang memungkinkan pengguna belajar di mana saja dan kapan saja [4]. The Flexible Learning Advisory Group (FLAG) mendefinisikan e-learning sebagai berikut:

"e-learning is defined as a wide set of applications and processes which use all available electronic media todeliver vocational education and training" [6].

Manfaat dari e-learning di antaranya [1]:

1 E-learning membuat biaya studi lebih ekonomis karena pengguna dapat belajar pada waktu dan tempat mereka sendiri. 
2 Pengguna dapat mengakses materi belajar setiap saat dan berulang-ulang sehingga pengguna dapat lebih memantapkan penguasaannya terhadap materi pembelajaran.

3 E-learning dapat disesuaikan dengan kecepatan belajar masing-masing pengguna. Apabila pengguna belum mengerti dan memahami materi tertentu, maka ia dapat mengulanginya lagi sampai paham.

4 E-learning dapat menciptakan model pembelajaran yang lebih kreatif dan menyenangkan dengan memanfaatkan multimedia atau yang lainnya.

5 E-learning memberikan kesempatan bagi pengguna untuk menyesuaikan pembelajaran dengan gaya hidup mereka, termasuk orang-orang yang sibuk sekali pun seperti kalangan pekerja dan profesional untuk dapat menerima pembelajaran.

Teman Belajar hadir untuk dapat menyesuaikan pembelajaran, termasuk orang yang sibuk sekali pun untuk dapat mengupgrade skill dan wawasannya yang berguna untuk meningkatkan karier mereka. Teman Belajar merupakan sebuah aplikasi e-learning yang berbasis android. Teman Belajar dikembangkan dengan bahasa pemrograman java dan XML serta database MySQL. Teman Belajar menyediakan materi umum untuk pengguna mulai dari SD sampai SMA, profesional, dan juga kalangan umum. Pengguna pada Teman Belajar dapat dibagi menjadi menjadi dua, yaitu sebagai pencari soal dan pembuat soal. Pengguna dapat mengikuti tes untuk menjadi pembuat soal. Dengan demikian, dapat dihasilkan pembuat soal yang berkualitas.

Teman Belajar juga menyediakan pembelajaran yang interaktif. Pengguna dapat menghubungi pembuat soal melalui fasilitas chat untuk bisa bertanya langsung jika ada materi yang belum dipahami pada waktu-waktu tertentu.

\section{METODE PENELITIAN}

Metode yang digunakan untuk mengembangkan aplikasi e-learning Teman Belajar adalah dengan model waterfall. Model waterfall disebut model sekuensial linier (sequential linier) atau alur hidup klasik (classic life cycle) [7]. Model waterfall adalah suatu proses pengembangan perangkat lunak berurutan, di mana kemajuan dipandang sebagai terus mengalir ke bawah (seperti air terjun) [8]. Disebut dengan waterfall karena tahap demi tahap yang dilalui harus menunggu selesainya tahap sebelumnya dan berjalan berurutan. Tahapan pada model waterfall antara lain requirements definition, system and software design, implementation dan unit testing, integration and system testing, and operation and maintenance [9].

\section{HASIL DAN PEMBAHASAN}

\section{Analisis Sistem}

Tahapan perancangan aplikasi e-learning Teman Belajar ini mengacu pada perancangan berbasis objek. Dalam penelitian ini penulis menggunakan Unified Modeling Language (UML). UML adalah sebuah bahasa yang berdasarkan grafik atau gambar untuk memvisualisasi, menspesifikasikan, membangun, dan mendokumentasikan sebuah sistem pengembangan software berbasis $\mathrm{OO}$ (Object-Oriented) [10]. Salah satu diagram UML, yaitu use case diagram. Use case diagram menggambarkan external view dari sistem yang akan kita buat modelnya. Use case diagram merupakan pemodelan dengan mendeskripsikan tipikal interaksi antara user sebuah sistem dengan sistemnya sendiri melalui sebuah cerita bagaimana sistem itu dipakai [11]. Use case diagram digunakan untuk menggambarkan aktor pada Teman Belajar dan aktivitas apa saja yang dapat 
dilakukan. Aktor terdiri dari admin dan pengguna. Admin bertugas untuk memanajemen semua aktivitas yang ada pada Teman Belajar. Pengguna pada Teman Belajar ini dapat dibagi menjadi dua fungsi, yaitu sebagai pencari soal dan pembuat soal.

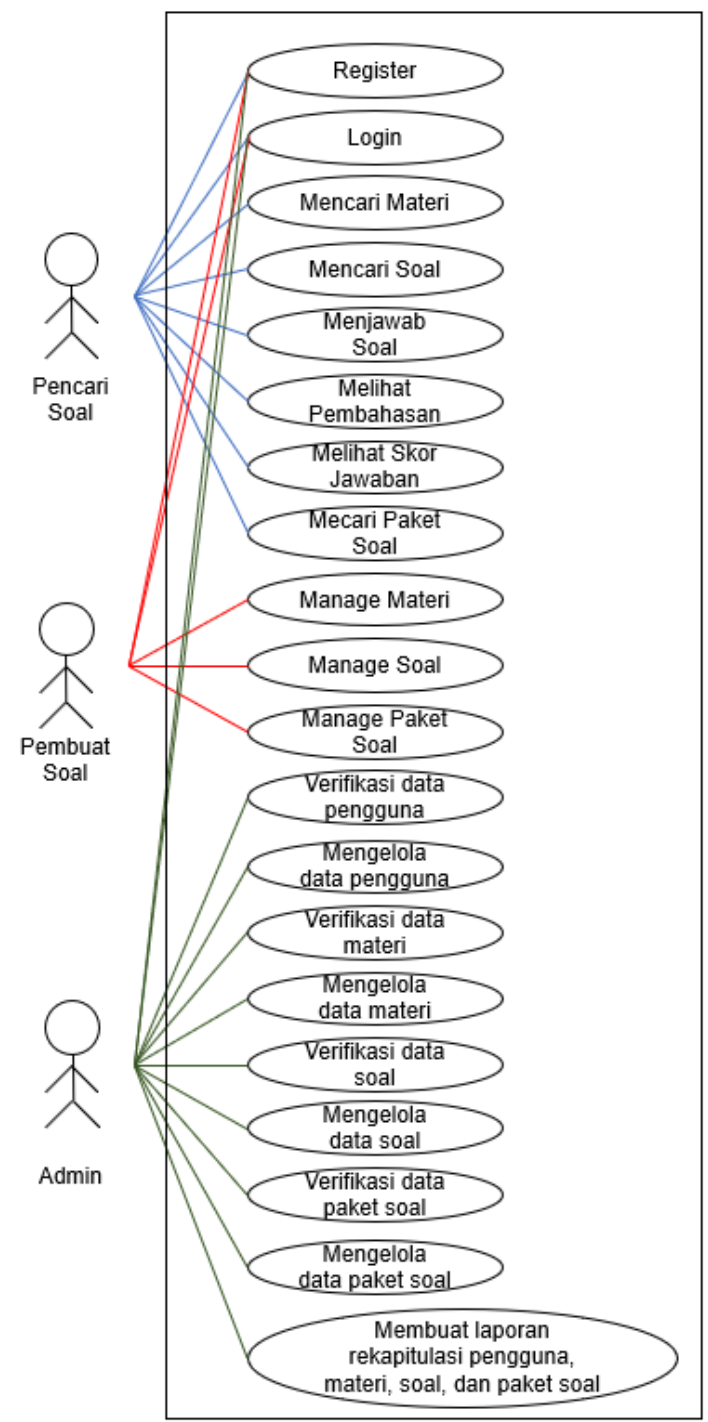

\section{Gambar 1. Use Case Diagram Teman Belajar}

Pada diagram use case (gambar 1) ada tiga aktor, yaitu pengguna (sebagai pencari soal dan pembuat soal) dan admin. Pencari soal dapat melakukan aktivitas seperti register, login, mencari materi, mencari soal, menjawab soal, melihat pembahasan, melihat skor jawaban, dan mencari paket soal.

Pencari soal dapat melakukan pencarian soal dengan memilih menu cari soal. Kemudian, pencari soal dapat memilih soal sesuai kebutuhan. Alurnya dapat dilihat pada activity diagram di bawah (gambar 2).

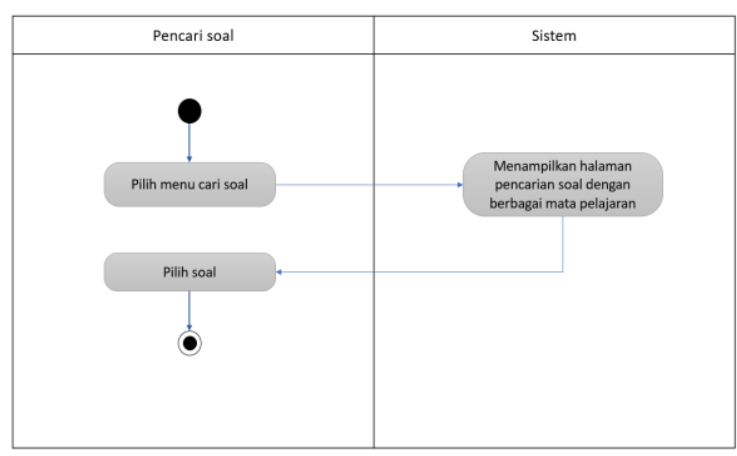

Gambar 2. Activity Diagram Mencari Soal

Pembuat soal dapat melakukan aktivitas seperti register, login, manage materi, manage soal, dan manage paket soal. Manage di sini artinya pembuat soal dapat membuat soal, mengubah atau mengupdate soal, dan menghapus soal.

Pembuat soal yang akan membuat soal dapat memilih menu manage soal. Kemudian, pembuat soal dapat mengatur untuk mengubah atau menghapus soal. Alurnya dapat dilihat pada activity diagram di bawah (gambar 3).

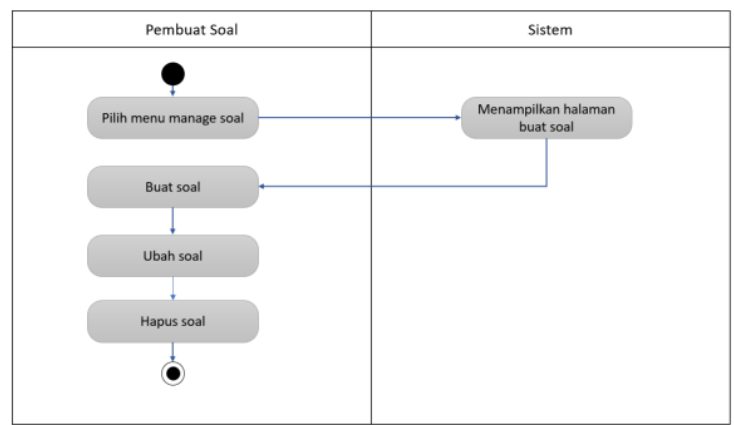

Gambar 3. Activity Diagram Membuat Soal

Admin dapat melakukan aktivitas seperti register, login, melakukan verifikasi data pengguna, mengelola data pengguna, melakukan verifikasi data materi, mengelola data materi, melakukan verifikasi data soal, mengelola data soal, 
STRING (Satuan Tulisan Riset dan Inovasi Teknologi)

Vol. 5 No. 3 April 2021

melakukan verifikasi data paket soal, mengelola data paket soal, membuat laporan rekapitulasi pengguna, materi, soal, dan paket soal.

\section{Implementasi}

Sebelum memulai aktivitas pada Teman Belajar, pengguna memasukki halaman utama Teman Belajar (gambar 4).

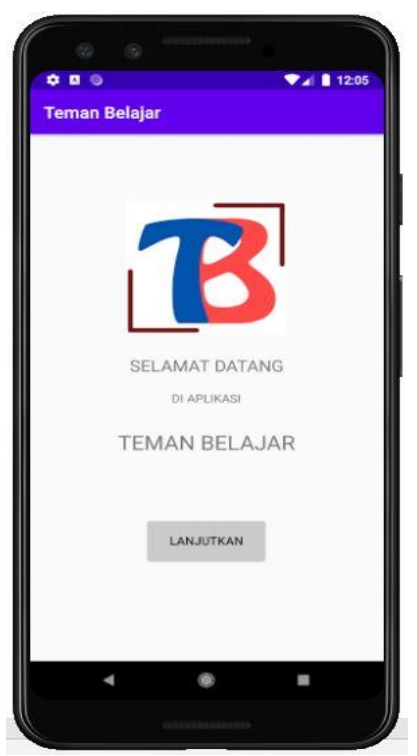

\section{Gambar 4. Halaman Utama Antarmuka Pengguna}

Setelah menekan tombol lanjutkan, pengguna masuk ke halaman login (gambar 5). Pada halaman ini, jika belum memiliki akun, pengguna bisa menekan tombol daftar untuk mendaftarkan akunnya.

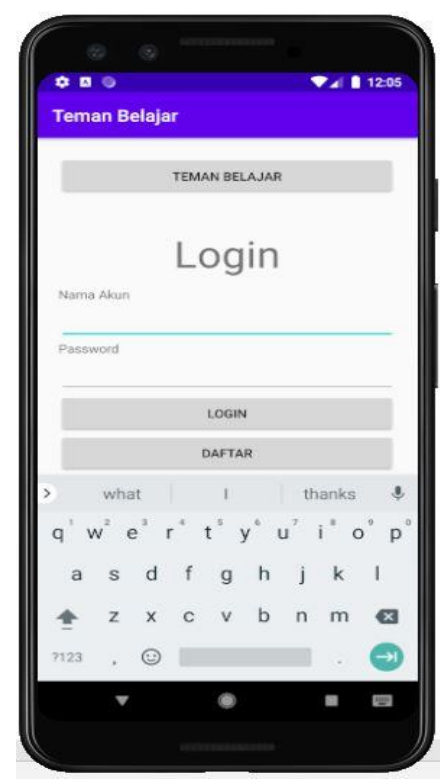

Gambar 5. Halaman Login Pengguna

Jika telah memiliki akun, pengguna dapat langsung mengisikan nama akun dan password. Secara default, pengguna terdaftar sebagai pencari soal. Setelah berhasil login, pencari soal akan masuk ke halaman beranda (gambar 6).

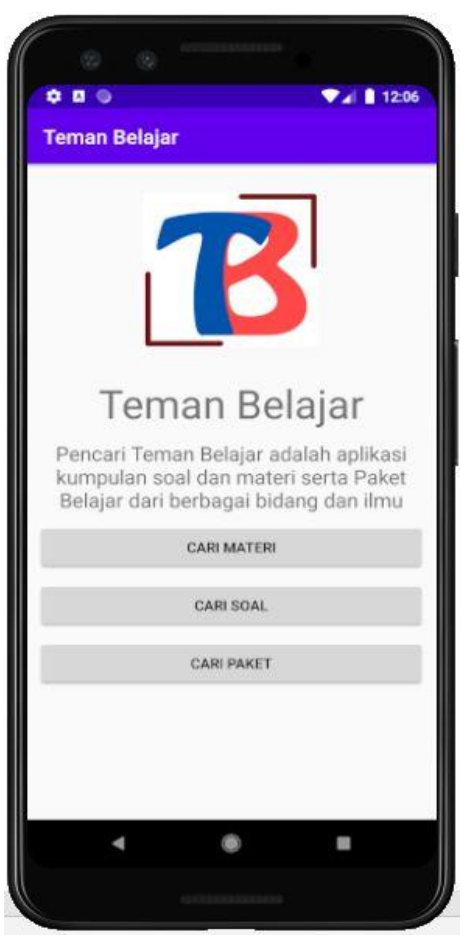

Gambar 6. Halaman Beranda Setelah Pencari Soal Login 
Pada halaman beranda ini, pencari soal dapat melakukan aktivitas seperti pencarian soal, pencarian materi, dan pencarian paket soal. Pencari soal dapat menjadi pembuat soal pada Teman Belajar dengan mengikuti tes terlebih dahulu. Jika lulus tes, pencari soal dapat menjadi pembuat soal. Pada Teman Belajar, jika pembuat soal telah login, terdapat menu tambahan pada navigasinya, yaitu menu manage materi, manage soal, dan manage paket (gambar 7). Pada menu tambahan ini, pembuat soal dapat melakukan pembuatan materi, soal, dan paket soal.

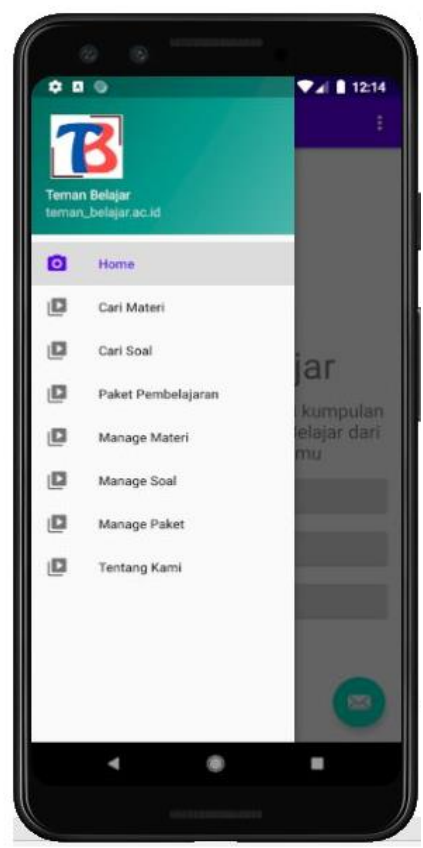

\section{Gambar 7. Halaman Beranda Setelah Pembuat Soal Login}

Pencari soal yang ingin mencari materi yang dibutuhkan dapat memilih menu cari materi pada (gambar 6). Setelah itu, sistem akan masuk ke halaman pencarian materi (gambar 8).

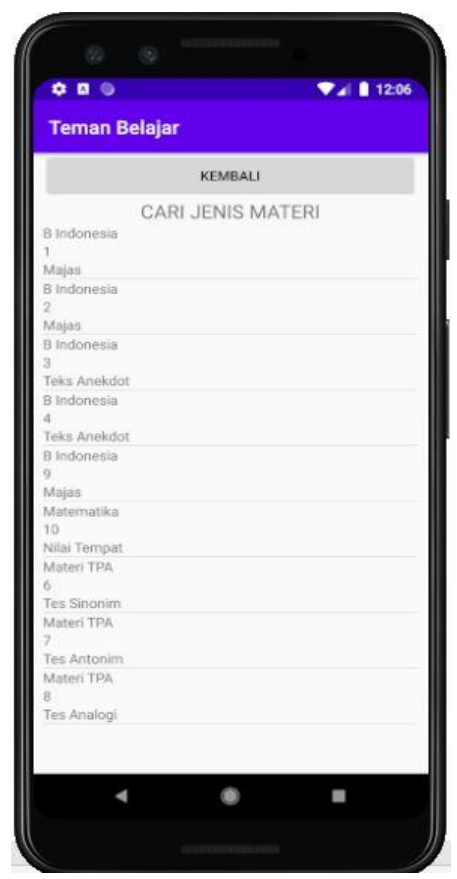

\section{Gambar 8. Halaman Pencarian Materi}

Pada halaman ini terdapat banyak jenis materi yang berbeda dan berbagai tingkatan. Pencari soal dapat memilih materi yang dibutuhkan. Setelah memilih jenis materi, sistem akan masuk ke halaman detail materi (gambar 9).

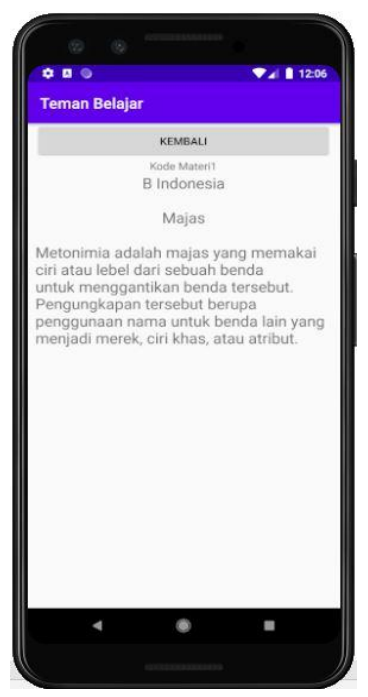

\section{Gambar 9. Halaman Detail Materi}

Pada halaman ini, pencari soal dapat membaca lebih detail materi yang telah dipilih. Kemudian, apabila ingin mencari paket soal, pencari soal dapat memilih menu cari paket pada (gambar 6). Setelah 
itu, sistem akan masuk ke halaman pencarian paket soal (gambar 10). Pada halaman ini, terdapat beberapa paket soal yang dapat dipilih pencari soal.

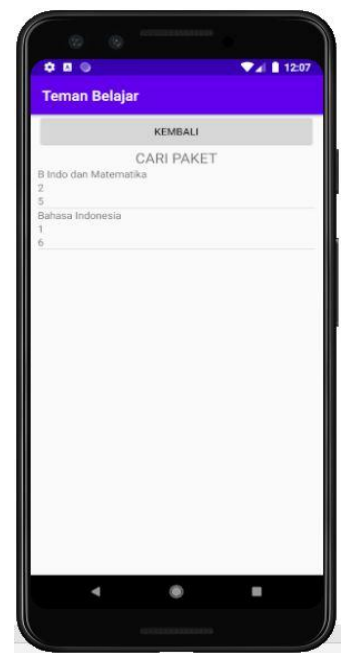

\section{Gambar 10. Halaman Pencarian Paket Soal}

Selain itu, pencari soal juga dapat memilih soal-soal yang dibutuhkan dengan menekan tombol cari soal pada (gambar 6). Lalu, sistem akan masuk ke halaman pencarian soal (gambar11).

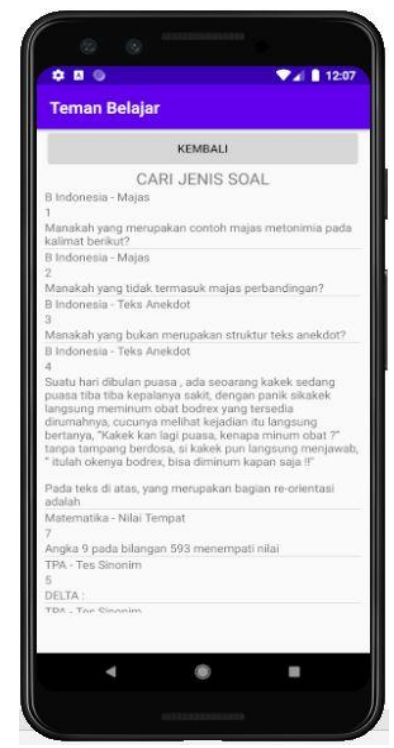

\section{Gambar 11. Halaman Pencarian Soal}

Pada halaman ini, terdapat list soal-soal dengan berbagai mata pelajaran. Kemudian, untuk lebih memantapkan pemahaman materi, pencari soal dapat langsung mengerjakan soal tersebut.
Setelah memilih soal yang diinginkan, sistem akan masuk ke halaman pengerjaan soal (gambar 12).

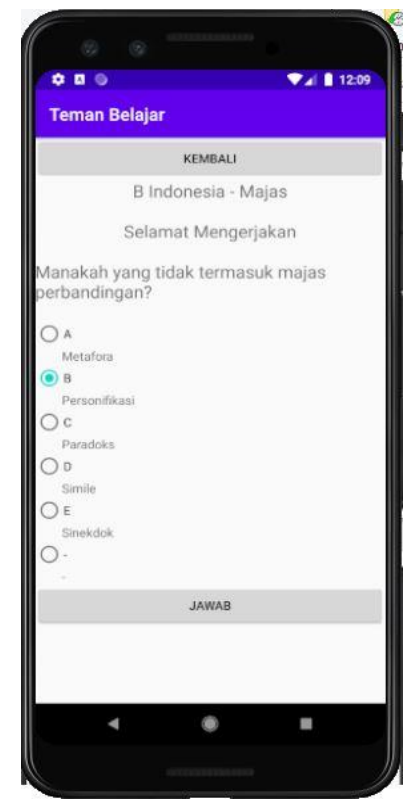

\section{Gambar 12. Halaman Pengerjaan Soal}

Pada halaman ini, pencari soal dapat menjawab soal yang telah dipilih tadi. Setelah menjawab soal tersebut, pencari soal dapat langsung mengetahui apakah jawaban yang telah dipilih tadi salah atau benar. Jika jawaban yang dipilih salah, akan muncul keterangan bahwa jawaban yang dipilih salah. Pada halaman ini juga akan ditampilkan kunci jawaban dan pembahasan soalnya. Begitu pun jika pencari soal menjawab soal dengan benar, akan muncul keterangan bahwa jawaban yang dipilih benar serta pembahasan soalnya. Setelah itu, pencari soal dapat melihat nilai yang diperolehnya di halaman skor jawaban.

\section{Pengujian}

Pada penelitian ini, pengujian dilakukan dengan menggunakan black box testing untuk mengetahui dan memastikan fungsi dari fitur-fitur aplikasi yang dibangun dapat bekerja dengan baik sehingga layak untuk digunakan. Black box testing merupakan pengujian perangkat lunak yang merupakan tes fungsionalitas dari 
aplikasi yang tidak mengacu pada struktur internal atau tidak membutuhkan pengetahuan khusus pada kode program aplikasi dan pengetahuan pemrograman [12]. Black box testing merupakan pengujian yang dilakukan dengan mengamati hasil eksekusi melalui data uji dari perangkat lunak [13]. Black box testing dilakukan untuk menemukan fungsi yang tidak benar atau tidak ada, kesalahan antarmuka (interface errors), kesalahan pada struktur data dan akses basis data, kesalahan performansi (performance errors), dan kesalahan inisialisasi dan terminasi [14]. Dengan metode ini, dapat diketahui jika fungsionalitas masih dapat menerima masukan data yang tidak diharapkan, maka menyebabkan data yang disimpan kurang valid [15]. Pengujian aplikasi e-learning Teman Belajar dilakukan pada beberapa smartphone android. Hasil pengujian dapat dilihat pada tabel 1.

Tabel 1. Hasil Pengujian Dengan Metode Black Box

\begin{tabular}{cccccc}
\hline No & Merk & Type & $\begin{array}{c}\text { Versi } \\
\text { OS }\end{array}$ & $\begin{array}{c}\text { Tampilan } \\
\text { Layout }\end{array}$ & Error \\
\hline 1 & Samsung & Note 8 & 9.0 .1 & Baik & $\begin{array}{c}\text { Tidak } \\
\text { Ada }\end{array}$ \\
2 & Xiaomi & $\begin{array}{c}\text { Redmi } \\
\text { Note } 4\end{array}$ & 7.0 .1 & Baik & $\begin{array}{c}\text { Tidak } \\
\text { Ada }\end{array}$ \\
3 & Oppo & A37 & 5.1 .1 & Baik & $\begin{array}{c}\text { Tidak } \\
\text { Ada }\end{array}$ \\
4 & Oppo & F1 & 9.0 .1 & Baik & $\begin{array}{c}\text { Tidak } \\
\text { Ada }\end{array}$ \\
\hline
\end{tabular}

Setelah penulis melakukan pengujian terhadap aplikasi e-learning Teman Belajar pada smartphone tersebut, aplikasi dapat diinstal dan digunakan serta dapat berjalan dengan lancar dan cepat. Perbedaan hanya terdapat pada kualitas warna, kecerahan gambar, dan pada smartphone yang memiliki resolusi lebih kecil. Juga kecerahan warna dari model yang ditampilkan akan lebih bagus apabila menggunakan smartphone yang memiliki resolusi gambar yang tinggi.
Penggunaan versi Operating System (OS) yang berbeda dari masing-masing smartphone dinilai cukup menjadi perbedaan yang berpengaruh besar dalam proses menjalankan aplikasi. Semakin besar tingkatan versi OS, maka semakin cepat smartphone dalam menjalankan aplikasi tersebut. Namun, dari hasil pengamatan dan penggambaran terhadap keempat smartphone yang dijadikan uji aplikasi, tidak ditemukan kerusakan atau error pada aplikasi, baik dalam proses instalasi maupun dalam proses menjalankan aplikasi.

\section{SIMPULAN}

Pemanfaatan aplikasi e-learning dapat memberikan dukungan bagi pengguna di tengah tingginya persaingan dalam dunia pendidikan dan pekerjaan. Aplikasi $e$ learning yang bersifat fleksibel dapat memudahkan pengguna untuk dapat belajar dan mengembangkan diri di mana pun dan kapan pun. Aplikasi e-learning Teman Belajar hadir untuk mendukung proses pembelajaran pengguna yang berisi materi umum yang dapat dipilih sesuai kebutuhan mulai dari tingkat SD sampai pekerja atau profesional.

Untuk pengembangan selanjutnya, pada aplikasi $e$-learning Teman Belajar ini dapat ditambahkan fitur multimedia agar lebih menarik terutama untuk anak-anak. Seperti menambahkan game edukasi dengan tema "Battle learning", di mana anak yang satu dapat berinteraksi dengan anak yang lainnya dan permainan itu berpacu untuk mendapatkan nilai tertinggi. Anak yang mendapatkan nilai tertinggi tadi akan mendapatkan poin bintang dan nantinya akan bertanding lagi dengan anak lainnya untuk memperebutkan nilai tertinggi. Permainan ini dapat mengasah kecepatan anak dalam menjawab soal dan lebih aktif di Teman Belajar. Terlebih anak-anak memiliki sifat suka berkompetisi. Selain itu, dapat ditambahkan dengan fitur video agar pembelajaran lebih interaktif. 


\section{DAFTAR PUSTAKA}

[1] R. Lailatu, "Konsep E-learning Dan Aplikasinya Pada Lembaga Pendidikan Islam," An Nur, vol. 1, 2011, doi: 10.24042/atjpi.v8i1.2099.

[2] M. Najieb, "Pengaruh Kualitas Produk terhadap Kepuasan Konsumen Produk Zenius Education [Skripsi]," 2018.

[3] D. Rahamawan, J. N. Mahameruaji, and P. A. J, "The Potential of Youtube As Educational Media for Young People," Edulib, vol. 8, no. 1, pp. 81-98, 2018, [Online]. Available:

https://ejournal.upi.edu/index.php/ed ulib/article/view/11267/PDF.

[4] Epignosis, "e-learning Concepts, Trends, Applications," Book, p. 5, 2014, [Online]. Available: https://www.talentlms.com/elearnin g/elearning-101-jan2014-

v1.1.pdf\%0Ahttp://www.talentlms.c om/elearning/elearning-101-

jan2014-v1.1.pdf.

[5] N. S. Hanum, "Keefetifan e-learning sebagai media pembelajaran (studi evaluasi model pembelajaran elearning SMK Telkom Sandhy Putra Purwokerto)," J. Pendidik. Vokasi, vol. 3, no. 1, pp. 90-102, 2013, doi: 10.21831/jpv.v3i1.1584.

[6] J. Mitchell and M. John, "EBusiness and Online Learning: Connections and Opportunities for Vocational Education and Training.," Aust. Natl. Train. Auth., p. 6, 2003, [Online]. Available: https://www.ncver.edu.au/_data/ass ets/file/0014/4802/nr1f05.pdf\%0Aht tps://login.ezproxy.net.ucf.edu/login ?auth=shibb\&url=http://search.ebsc ohost.com/login.aspx?direct=true \&d $\mathrm{b}=$ eric $\& A N=E D 476483 \&$ site $=$ ehost -live.
[7] M. Tabrani and E. Pudjiarti, "PENERAPAN METODE WATERFALL PADA SISTEM INFORMASI INVENTORI PT. PANGAN SEHAT SEJAHTERA," J. Infokar, vol. 1, 2017.

[8] C. Tristianto, "Penggunaan Metode Waterfall untuk Pengembangan Sistem Monitoring dan Evaluasi Pembangunan Pedesaan," J. Teknol. Inf. ESIT, 2018, doi: 10.1093/nq/182.23.321-a.

[9] R. A. Pascapraharastyan, A. Supriyanto, and P. Sudarmaningtyas, "Rancang Bangun Sistem Informasi Manajemen Arsip Rumah Sakit Bedah Surabaya Berbasis Web," Sist. Inf., vol. 3, no. 1, pp. 72-77, 2014.

[10] Suendri, "Implementasi Diagram UML (Unified Modelling Language) Pada Perancangan Sistem Informasi Remunerasi Dosen Dengan Database Oracle (Studi Kasus: UIN Sumatera Utara Medan)," J. Ilmu Komput. dan Inform., vol. 3, no. 1, pp. 1-9, 2018, [Online]. Available: http://jurnal.uinsu.ac.id/index.php/al goritma/article/download/3148/187.

[11] D. W. T. Putra and R. Andriani, "Unified Modelling Language (UML) dalam Perancangan Sistem Informasi Permohonan Pembayaran Restitusi SPPD," J. Teknolf, vol. 7, no. 1 , p. 32, 2019, doi: 10.21063/jtif.2019.v7.1.32-39.

[12] D. Febiharsa, I. M. Sudana, and N. Hudallah, "Uji Fungsionalitas (BlackBox Testing) Sistem Informasi Lembaga Sertifikasi Profesi (SILSP) Batik Dengan AppPerfect Web Test Dan Uji Pengguna," JOINED J., vol. 1, no. 2, pp. 117-126, 2018, [Online]. 
Available:

http://ejournal.ivet.ac.id/index.php/jiptika/a rticle/view/752.

[13] U. Hanifah, R. Alit, and S. Sugiarto, "Penggunaan Metode Black Box Pada Pengujian Sistem Informasi Surat Keluar Masuk," SCAN - J. Teknol. Inf. dan Komun., vol. 11, no. 2, pp. 33-40, 2016, [Online].

Available:

http://ejournal.upnjatim.ac.id/index. $\mathrm{php} / \mathrm{scan} / \mathrm{article} / \mathrm{view} / 643$.

[14] M. S. Mustaqbal, R. F. Firdaus, and H. Rahmadi, "PENGUJIAN
APLIKASI MENGGUNAKAN BLACK BOX TESTING BOUNDARY VALUE ANALYSIS

(Studi Kasus : Aplikasi Prediksi Kelulusan SNMPTN)," vol. I, no. 3, pp. 31-36, 2015.

[15] W. N. Cholifah, Y. Yulianingsih, and S. M. Sagita, "Pengujian Black Box Testing pada Aplikasi Action \& Strategy Berbasis Android dengan Teknologi Phonegap," STRING (Satuan Tulisan Ris. dan Inov. Teknol., vol. 3, no. 2, p. 206, 2018, doi: 10.30998/string.v3i2.3048. 